AECIVISO

DEC 021998

OSTI

\title{
Task 6.3/6.7.4 - Silicon Carbide Joining
}

\author{
Semi-Annual Report \\ July 1 - December 31, 1997 \\ By:
John P. Kay
John P. Hurley
}

Work Performed Under Contract No.: DE-FC21-93MC30097

For

U.S. Department of Energy

Office of Fossil Energy

Federal Energy Technology Center

P.O. Box 880

Morgantown, West Virginia 26507-0880

By

Energy \& Environmental Research Center

University of North Dakota

P. O. Box 9018

Grand Forks, North Dakota 58202-9018 


\section{DISCLAIMER}

Portions of this document may be illegible in electronic image products. Images are produced from the best available original document. 


\section{DOE DISCLAIMER}

This report was prepared as an account of work sponsored by an agency of the United States Government. Neither the United States Government, nor any agency thereof, nor any of their employees makes any warranty, express or implied, or assumes any legal liability or responsibility for the accuracy, completeness, or usefulness of any information, apparatus, product, or process disclosed or represents that its use would not infringe privately owned rights. Reference herein to any specific commercial product, process, or service by trade name, trademark, manufacturer, or otherwise does not necessarily constitute or imply its endorsement, recommendation, or favoring by the United States Government or any agency thereof. The views and opinions of authors expressed herein do not necessarily state or reflect those of the United States Government or any agency thereof.

Available to the public from the National Technical Information Service, U.S. Department of Commerce, 5285 Port Royal Road, Springfield, VA 22161; phone orders accepted at (703) $487-4650$.

\section{ACKNOWLEDGMENT}

This report was prepared with the support of the U.S. Department of Energy (DOE) Federal Energy Technology Center, Cooperative Agreement No. DE-FC21-93MC30097. However, any opinions, findings, conclusions, or recommendations expressed herein are those of the author(s) and do not necessarily reflect the views of DOE.

\section{EERC DISCLAIMER}

LEGAL NOTICE This research report was prepared by the Energy \& Environmental Research Center (EERC), an agency of the University of North Dakota, as an account of work sponsored by the U.S. Department of Energy. Because of the research nature of the work performed, neither the EERC nor any of its employees makes any warranty, express or implied, or assumes any legal liability or responsibility for the accuracy, completeness, or usefulness of any information, apparatus, product, or process disclosed or represents that its use would not infringe privately owned rights. Reference herein to any specific commercial product, process, or service by trade name, trademark, manufacturer, or otherwise does not necessarily constitute or imply its endorsement or recommendation by the EERC. 


\section{TABLE OF CONTENTS}

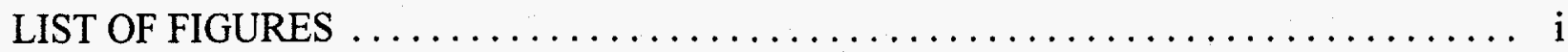

1.0 INTRODUCTION $\ldots \ldots \ldots \ldots \ldots \ldots \ldots \ldots \ldots \ldots \ldots \ldots \ldots \ldots \ldots \ldots \ldots$

2.0 OBJECTIVE $\ldots \ldots \ldots \ldots \ldots \ldots \ldots \ldots \ldots \ldots \ldots \ldots \ldots \ldots \ldots \ldots \ldots \ldots \ldots \ldots \ldots \ldots$

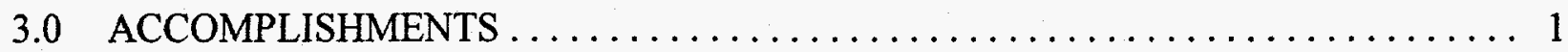

3.1 Preparation of Joining Material $\ldots \ldots \ldots \ldots \ldots \ldots \ldots \ldots \ldots \ldots \ldots \ldots \ldots$

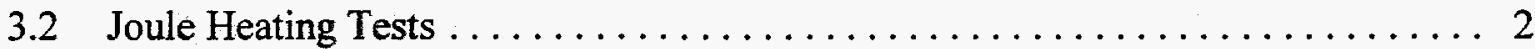

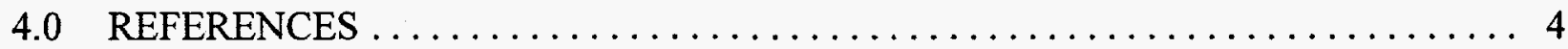

\section{LIST OF FIGURES}

1 SEM micrograph showing the porosity (white areas) of a joint composed of silicon and graphite in a molar mixture of $0.6 \ldots \ldots \ldots \ldots \ldots \ldots \ldots \ldots \ldots \ldots \ldots \ldots \ldots$

2 SEM micrograph of a pellet cross section showing bands of carbon paint caused during pressing 


\section{TASK 6.3/6.7.4 - SILICON CARBIDE JOINING}

\subsection{INTRODUCTION}

Future energy systems will be required to fire low-grade fuels and meet higher energy conversion efficiencies than today's systems. The steam cycle used at present is limited to a maximum temperature of $550^{\circ} \mathrm{C}$, because above that the stainless steel tubes deform and corrode excessively. To boost efficiency significantly, much higher working fluid temperatures are required. Although high-temperature alloys will suffice for the construction of these components in the near-term, the greatest efficiency increases can only be reached with the use of advanced structural ceramics such as silicon carbide (SiC). However, $\mathrm{SiC}$ does not melt, but instead sublimes at temperatures over $2000^{\circ} \mathrm{C}$. Therefore, it is not possible to join pieces of it through welding, and most brazing compounds have much lower melting points so the joints lose strength at temperatures much lower than the maximum use temperature of the SiC. Since larger objects, such as heat exchangers, cannot be easily created from smaller ceramic pieces, the size of the $\mathrm{SiC}$ structures that can presently be manufactured are limited by the size of the sintering furnaces (approximately 10 feet for sintered alpha silicon carbide). In addition, repair of the objects will require the use of field joining techniques. Some success has been made by causing silicon and carbon to react at $1400^{\circ}-1500^{\circ} \mathrm{C}$ to form $\mathrm{SiC}$ in a joint (Rabin, 1995) but these joints contain continuous channels of unreacted silicon which cause the joints to corrode and creep excessively at temperatures below $1260^{\circ} \mathrm{C}$ (Breder, 1996). At present, no joining techniques are available that allow sintered alpha $\mathrm{SiC}$ to be used to its full potential.

\subsection{OBJECTIVE}

The objective of this work is to develop a patentable technique for joining large silicon carbide structures in the field. The key to developing a successful technique will be the use of reactive joining compounds to lower the joining temperature without leaving continuous channels of unreacted compounds that can weaken the joint at temperatures below $1260^{\circ} \mathrm{C}$ or serve as conduits for transport of corrodents. Special efforts will be made in this project to transfer the developed technologies to the materials industry via licensing agreements through the Energy \& Environmental Research Center (EERC) Foundation.

\subsection{ACCOMPLISHMENTS}

\subsection{Preparation of Joining Material}

Previous pellet materials were prepared by combining silicon carbide, graphite, and silicon powders with a solvent, binder, and plasticizer. Two size ranges of $\mathrm{SiC}$ were used to increase the packing efficiency of the material. The materials were mixed in a mortar with a pestle for 15 minutes and allowed to dry. After drying, the mixture was broken up into a uniform powder and pressed into pellets. However, the pellets had a relatively low green strength, and the joints 
were weak, possibly because of insufficient mixing of the silicon and graphite and poor packing, leading to low levels of silicon carbide formation during the joining process.

To examine the formation of silicon carbide during joule heating, pellets were made which only contained silicon and graphite powder. These powders were combined in varying molar ratios of silicon to graphite. Joints created with pellets of this composition were very porous and therefore displayed low strength. Four-point flexural tests revealed strengths of $20-30 \mathrm{MPa}$ (2900-4350 psi). Figure 1 is a scanning electron microscopy (SEM) micrograph showing a joint made with a molar ratio of silicon to graphite of 0.6. Indium foil was used to fill the pores during sample preparation so that they would show as bright white in backscattered electron imaging. The micrograph clearly shows the magnitude of porosity displayed by the silicon and graphite reaction. SEM results of the joint showed an overall porosity of $48 \%$, with $11 \%$ excess silicon and $3 \%$ excess carbon. Porosity was not distributed uniformly throughout the joint, but rather the joint contained areas with porosity as high as $73 \%$ and as low as $15 \%$. Sizes of some pore spaces were in the tens of microns. This leads to the conclusion that the material was not mixed well. No continuous channels of silicon could be detected. If strength is to be increased, porosity must be greatly reduced. To reduce porosity, more intimate contact must be made between the carbon source and the silicon metal and another material must be added to the mix to aid in the reduction of the size of the voids.

$\mathrm{SiC}$ produced from the reaction of silicon and graphite has only $69 \%$ of the volume of the original materials. This volume reduction causes porosity to form in the joint. To reduce the amount of porosity, $\mathrm{SiC}$ powder was introduced in the pellet mixture. The carbon source was also changed to polystyrene and carbon paste in an attempt to improve the silicon-carbon interaction within the joint. In one formulation, silicon metal powder was added to polystyrene in proper $\mathrm{Si} / \mathrm{C}$ molar ratios, mixed in the presence of toluene, and allowed to dry. The resultant mix was then pyrolized which produced carbon-coated silicon metal particles. The coated particles were then mixed with silicon carbide powder. The second formulation involved mixing silicon metal powder with carbon paste. After drying, the mixture was added to silicon carbide powder.

Carbon paint was shown to be ineffective as a carbon source. During pressing, the carbon paint tended to flow and concentrate in zones. Figure 2 shows an SEM micrograph of a pressed pellet displaying carbon paint-rich zones. Early trials with the polystyrene method show promise, but more work needs to be done. The SEM analysis work has been delayed because of equipment damage and replacement caused by spring 1997 flooding but should resume in full during the next quarter.

\subsection{Joule Heating Tests}

No matter what compounds are used in joining $\mathrm{SiC}$, heat must be applied to the joint. Most often, the heat comes from an external source, such as a furnace. Sometimes inductive heating or microwave heating is used, but in each of these cases, the object needs to be surrounded by the heater. This is not a problem for objects that are small in at least two dimensions, such as a pipe. For objects that are large in two dimensions, such as heat exchanger panels, these heating methods are not applicable. Instead, we are attempting to connect electrodes to either side of a 


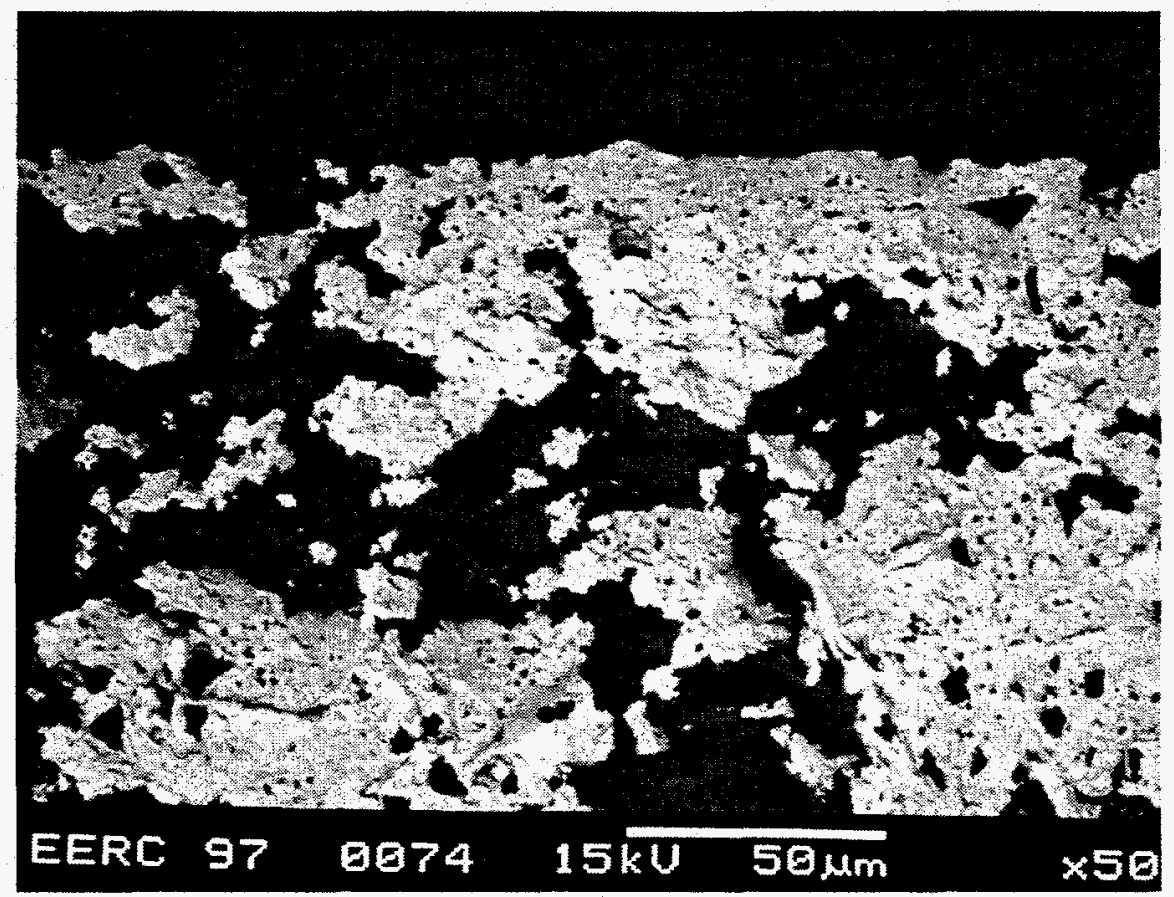

Figure 1. SEM micrograph showing the porosity (white areas) of a joint composed of silicon and graphite in a molar mixture of 0.6. The top of the micrograph is the Hexoloy bar.

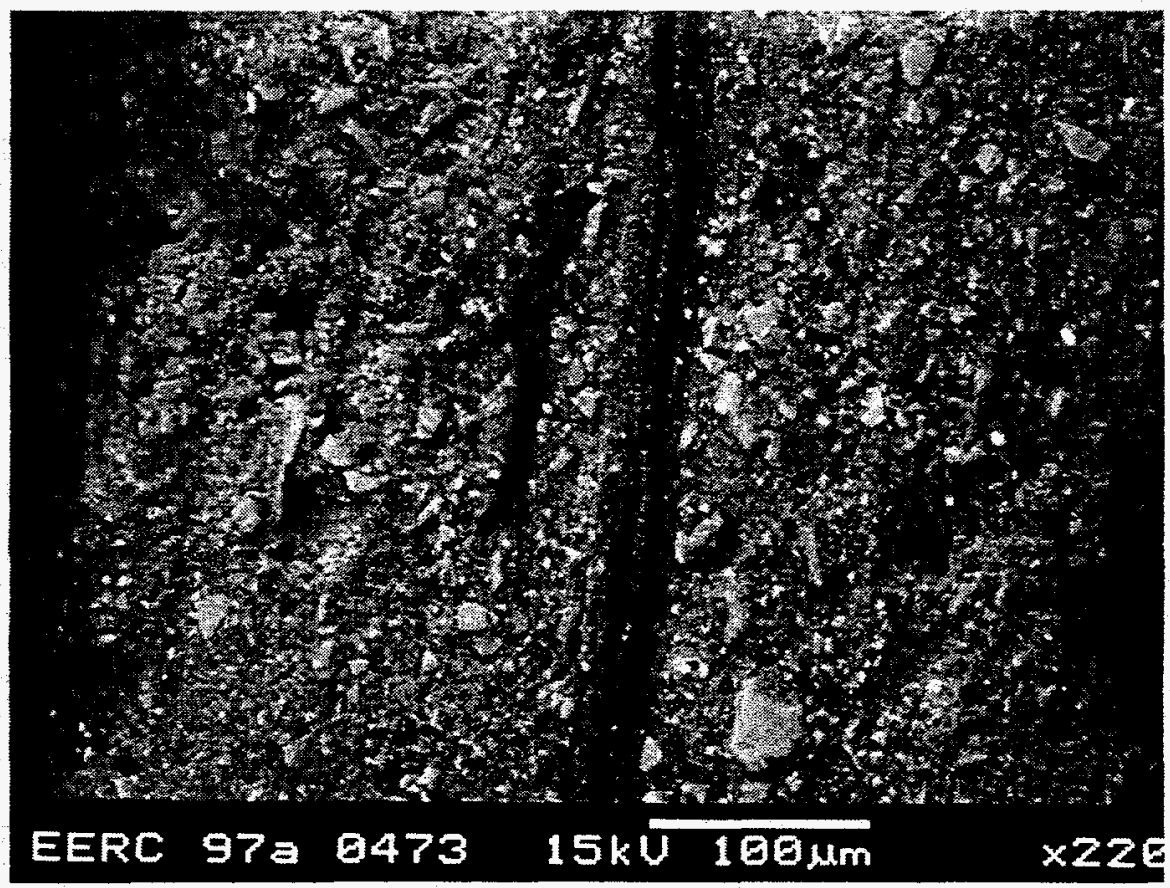

Figure 2. SEM micrograph of a pellet cross section showing bands of carbon paint caused during pressing. 
$\mathrm{SiC}$ joint and pass an electric current through the material to cause resistive or Joule heating. With proper attachment of the electrodes, combined with the high thermal conductivity of SiC, heating of the joint could be made very uniform, and very large structures could be heated. This method has an additional advantage because the joint is placed in an electrical field known to reduce the temperature necessary for reaction between ceramic precursors-a technique known as combustion synthesis. This is an especially valuable attribute in cases where the joining is accomplished by reaction sintering. However, no joining tests were performed this quarter, since we are awaiting the results of the SEM analyses of the joints prepared previously.

\subsection{REFERENCES}

1. Breder, K.; Parten, R.J. "Strength and Corrosion Behavior of SiC-Based Ceramics in Hot Coal Combustion Environments," in Proceedings of the Tenth Annual Conference on Fossil Energy Materials; ORNL/CONF-9605167, 1996; pp 53-62.

2. Rabin, B.H. "Joining of $\mathrm{SiC}$ Ceramics and $\mathrm{SiC} / \mathrm{SiC}$ Composites," in Proceedings of the Ninth Annual Conference on Fossil Energy Materials; ORNL/CONF-9505204, 1995; pp 41-44. 